\title{
Label free aptasensor for lysozyme detection; a comparison of the analytical performance of the two aptamers
}

\author{
Cristina Ocaña ${ }^{\mathrm{a}, \mathrm{b}}$, Akhtar Hayat $^{\mathrm{b}, \mathrm{c}}$, Rupesh Mishra $^{\mathrm{b}}$, Alina Vasilescu ${ }^{\mathrm{d}}$, Manel del Valle ${ }^{\mathrm{a}}$ \\ and Jean-Louis Marty ${ }^{b^{*}}$
}

${ }^{a}$ Sensors and Biosensors Group, Department of Chemistry, Universitat Autònoma de Barcelona, 08193 Bellaterra, Spain

${ }^{b}$ Université de Perpignan, Laboratoire IMAGES, EA 4218, 52 avenue Paul Alduy, bât. S, Perpignan cedex 66860, France

${ }^{c}$ Interdisciplinary Research Centre in Biomedical Materials (IRCBM), COMSATS Institute of Information Technology (CIIT), Lahore, Pakistan

${ }^{d}$ International Centre of Biodynamics, 1B Intrarea Portocalelor, sector 6, 060101, Bucharest, Romania

*Corresponding author: jlmarty@univ-perp.fr

\begin{abstract}
This work presents a comparison of two different aptamers (COX and TRAN) for the detection of the ubiquitous protein lysozyme using aptamer-based biosensors. The detection is based on the specific recognition by the aptamer immobilized on screen printed carbon electrodes (SPCEs) via diazonium coupling reaction. The quantitative detection of lysozyme protein was achieved by electrochemical impedance spectroscopy (EIS). Very good linear ranges and detection limits for the lysozyme detection were obtained, from 0.025 to $1 \mu \mathrm{M}$ and $725 \mathrm{nM}$ using aptamer $\mathrm{COX}$ and from 0.025 to $1 \mu \mathrm{M}$ and $31.7 \mathrm{nM}$ using aptamer TRAN. The obtained results showed that the developed aptasensors exhibit good specificity, stability and reproducibility for lysozyme detection. The aptasensors were also tested in wine samples; very good recovery rates were obtained in the range from 96.4 to $102 \%$ for lysozyme detection. The recovery rates confirm the reliability and suitability of the developed method in wine matrix. The developed method could be a useful and promising platform for detection of lysozyme in different applications.
\end{abstract}

Keywords: disposable aptasensor, lysozyme, diazonium chemistry, label free detection, wine samples. 


\section{Introduction}

Lysozyme (Lys) is a mucopolysaccharide alkaline enzyme very abundant and widely distributed in nature (1). This enzyme has the ability to destroy bacterial cellular membranes by catalyzing the breakage of the $\beta 1-4$ bond found in peptidoglycan residues of Gram-positive bacterium cell walls between N-acetylmuramic acid and $\mathrm{N}$ acetylglucosamine $(2,3)$. Lysozyme's relatively small size and simplicity makes it an excellent model analyte for novel methods in protein detection. In the field of winemaking, lysozyme from egg-white has been widely used to mitigate or prevent heterolactic fermentation (4). The maximum amount of lysozyme allowed in winemaking by the International Organization of Wine (OIV) is $500 \mathrm{mg} / \mathrm{L}(\sim 35 \mu \mathrm{M})(5)$. In addition, lysozyme is also used in the food industry including cheese (6-8) and in beer (9) production, as well as to prolong the shelf-life of shrimp, surimi products and sausages $(10,11)$. Besides its useful properties, low concentrations of lysozyme from egg-white are also associated with allergic reactions in susceptible individuals (12). Moreover, elevated human lysozyme level was reported in urine and serum in case of leukemia (13) and several kidney problems (14). Based on the above observation, the effective detection of lysozymes is of vital importance in the clinical and food fields.

At present, the available analytical methods for the detection of lysozymes are either chromatographic or immunosensing techniques based on ELISA. These methods have high sensitivity, but also many drawbacks, such as high cost and experimental complexity. To overcome these limitations, biosensors have been emerged as attractive alternatives to these conventional methods $(15,16)$. However the reported lysozyme biosensors involve complicated fabrication methodologies, and do not fulfill the requirement of a disposable and portable device to be used for onsite analysis. Moreover, their applications are limited to only a certain number of real samples (17). Hence, there is a need to develop new, rapid, cheap and effective biosensors for the detection of lysozyme in different matrices such as wine. Among the different types of detection techniques, electrochemical biosensors are gaining special interest due to their remarkable sensitivity, experimental simplicity and low cost $(18,19)$. In the last few years, among different electrochemical techniques reported, the use of Electrochemical Impedance Spectroscopy (EIS) (20) has been widely employed $(21,22)$ as a powerful 
analytical tool capable of detecting biological macromolecules at low concentration levels. EIS is based on applying an AC potential to an electrochemical cell and measuring the current that crosses through the cell. This methodology results in a very sensitive response to changes of the interfacial properties upon bio-recognition events taking place at the electrode surfaces $(23,24)$. Moreover, it does not require any special reagent, making it as cost-efficient technique for analytical analysis (25).

Nowadays, there is great interest in the development of aptasensors $(26,27)$. Aptamers are artificial DNA or RNA oligonucleotides selected in vitro which have the ability to bind to proteins, small molecules or even whole cells. Aptamers are capable of recognizing their targets with affinities and specificities often matching or even exceeding those of antibodies $(28,29)$. Ever since Cox and Ellington (31) obtained the first lysozyme-binding aptamer in 2001, different lysozyme-aptamers have been reported in the literature with varying binding affinities to their target analyte $(30,31)$. In this work, we design disposable and cost effective label free aptasensors, and compare the analytical performance of two label-free impedimetric aptasensors for lysozyme detection based on two different lysozyme aptamers. The transduction principle used is based on the change of electron-transfer resistance in the presence of a redox probe $\left[\mathrm{Fe}(\mathrm{CN})_{6}\right]^{3}-/\left[\mathrm{Fe}(\mathrm{CN})_{6}\right]^{4-}$ which can be measured by EIS. The aptamers were immobilized onto the electrode surface by covalent binding via diazonium salt. Both aptasensors showed appropriate response behavior values to determine Lys in spiked wine sample. Besides, the different aptasensors evaluated showed particular advantages, such as high sensitivity, simple instrumentation, low production cost and rapid response.

\section{Experimental}

\subsection{Chemicals and materials}

Potassium dihydrogen phosphate, potassium ferricyanide $\left(\mathrm{K}_{3}\left[\mathrm{Fe}(\mathrm{CN})_{6}\right]\right)$, potassium ferrocyanide $\left(\mathrm{K}_{4}\left[\mathrm{Fe}(\mathrm{CN})_{6}\right]\right)$, sodium monophosphate, bovine serum albumin (BSA), lysozyme (Lys), casein, magnesium chloride, potassium chloride, sodium chloride, ethanolamine, N-hydroxysuccinimide (NHS), N-(3-dimethylaminopropyle)-N'-ethylecarbodiimide hydrochloride (EDC), 4-aminobenzoic acid (ABA) and sodium nitrite 
were purchased from Sigma (St. Louis, MO, USA). All reagents were of analytical grade. The aptamers used were:

AptLysCOX(32)

5'-NH2-ATC AGG GCT AAA GAG TGC AGA GTT ACT TAG-3'

AptLysTRAN(31)

5'-NH ${ }_{2}$-GCA GCT AAG CAG GCG GCT CAC AAA ACC ATT CGC ATG CGG C-3' and were provided by Eurogentec, France.

All solutions were prepared using Milli Q water. The buffers employed were: binding buffer (BB) (1mM MgCL $2,2.7 \mathrm{mM} \mathrm{KCl}, 140 \mathrm{mM} \mathrm{NaCl}, 0.1 \mathrm{mM} \mathrm{Na}_{2} \mathrm{HPO}_{4}$ and $1.8 \mathrm{mM}$ $\mathrm{KH}_{2} \mathrm{PO}_{4} \mathrm{pH} 7.4$ ), PBS (187 mM NaCl, $2.7 \mathrm{mM} \mathrm{KCl}, 8.1 \mathrm{mM} \mathrm{Na} \mathrm{HPO}_{4} \cdot 2 \mathrm{H}_{2} \mathrm{O}, 1.76$ $\mathrm{mM} \mathrm{KH} \mathrm{PO}_{4}, \mathrm{pH} 7.4$ ) and $100 \mathrm{mM}$ MES buffer $10 \mathrm{nM}$ containing $0.09 \% \mathrm{NaCl}$.

\subsection{Apparatus}

The electrochemical measurements were performed using an Autolab PGSTAT100 potentiostat/galvanostat equipped with a frequency response analyzer system (Eco Chemie, Netherlands) controlled by two Autolab softwares; Frequency Response analyzer (4.9) for impedance and General purpose Electrochemical system (4.9) for voltammetry. Screen printed carbon electrodes (SPCEs) were fabricated using a DEK 248 screen-printing system. The SPCE consists of conventional three electrode configuration with graphite as working (4-mm diameter disk) and counter $(16 \mathrm{~mm} \times 1.5$ $\mathrm{mm}$ curved line) electrode, and $\mathrm{Ag} / \mathrm{AgCl}(16 \mathrm{~mm} \times 1.5 \mathrm{~mm}$ straight line $)$ as pseudo reference electrode. The impedance spectra were recorded using a sinusoidal ac potential perturbation of $5 \mathrm{mV}(\mathrm{rms})$, in the frequency range $10^{4}-0.5 \mathrm{~Hz}$, superimposed on a de potential of $0.095 \mathrm{~V}$.

\subsection{Experimental protocol}

The scheme of experimental protocol for lysozyme detection, described in detail below, and represented as Fig. 1.

$<$ Figure 1 $>$ 


\subsubsection{Covalent immobilization of Apt Lys onto the electrode surface}

SPCE was subjected to electrochemical pretreatment by 10 cyclic potential scans between 1.0 and $-1.5 \mathrm{~V}$ at scan rate of $0.2 \mathrm{~V} / \mathrm{s}$ in $0.5 \mathrm{M} \mathrm{H}_{2} \mathrm{SO}_{4}$ and $0.1 \mathrm{M} \mathrm{KCl}$. The electrode surface was modified by diazotation reaction. In brief, the diazonium cation was synthesized by in situ reaction of $2 \mu \mathrm{L}$ of $1 \mathrm{M} \mathrm{NaNO}$ and $1 \mathrm{~mL}$ of $2 \mathrm{mM}$ ABA prepared in $0.5 \mathrm{M} \mathrm{HCl}$. The mixture was left to react for $5 \mathrm{~min}$ at room temperature. $100 \mu \mathrm{L}$ of the mixture and $100 \mu \mathrm{L}$ of $0.5 \mathrm{M} \mathrm{HCl}$ were deposited onto the electrode surface and the electrochemical modification was performed by linear sweep voltammetry from 0.6 to $-0.8 \mathrm{~V}$. After modification, the electrode was rinsed three times with distilled water. The carboxylic groups onto the electrode surface were activated with $100 \mu \mathrm{L}$ of $100 \mathrm{mM}$ EDC and $25 \mathrm{mM}$ NHS in $100 \mathrm{mM}$ MES buffer for 1 hour. After rinsing three times with distilled water, $30 \mu \mathrm{L}$ of an optimal concentration of AptLysCOX/TRAN were incubated onto the electrode surface for 1 hour. After that, the electrodes were washed three times with BB to remove the unbound aptamer. In order to deactivate the remaining succinimide groups, the electrodes were incubated with $30 \mu \mathrm{L}$ of $1 \mathrm{M}$ ethanolamine solution for $1 \mathrm{~h}$. After washing with $\mathrm{BB}$, the electrodes were incubated with $30 \mu \mathrm{L}$ of $0.1 \%$ BSA solution for 1 hour in order to avoid nonspecific adsorption. The modified electrodes can be used directly for sensing or stored dry at $4{ }^{\circ} \mathrm{C}$ for several days without decrease in the sensitivity.

\subsubsection{Detection of Lysozyme}

For the detection of Lys, the aptamer modified electrodes were incubated for $1 \mathrm{~h}$ with the selected concentrations of Lys. Then, the aptasensors were rinsed with BB and electrochemical measurements were performed

\section{.2.3.3. Wine samples preparation}

Spiked wine samples were prepared by following a protocol from a previous study (33). Briefly, $200 \mu \mathrm{M}$ Lys was spiked in $1 \mathrm{~mL}$ of wine sample and allowed to stand for $3 \mathrm{~min}$. Further, $200 \mu \mathrm{L}$ of a $5 \mathrm{M} \mathrm{NaCl}$ solution containing $5 \%$ Tween-20 surfactant were added to $200 \mu \mathrm{L}$ of lysozyme-wine mixture and diluted to a final volume of $1 \mathrm{~mL}$ using $20 \mathrm{mM}$ 
MES buffer $\mathrm{pH} 6$ with $1 \mathrm{mM} \mathrm{MgCl}_{2}$. This mixture was further centrifuged at $5000 \mathrm{rpm}$ for $5 \mathrm{~min}$ and diluted using the buffer afore said in order to obtain the desired concentration of Lys.

\subsection{Impedimetric measurements}

Impedance experiments were carried out at an applied potential of $0.1 \mathrm{~V}$ (vs. $\mathrm{Ag} / \mathrm{AgCl}$ reference electrode) obtained from the redox potential of $\left[\mathrm{Fe}(\mathrm{CN})_{6}\right]^{3-} /\left[\mathrm{Fe}(\mathrm{CN})_{6}\right]^{4-}$ by $\mathrm{CV}$, with a range of frequency of $10 \mathrm{KHz}-0.5 \mathrm{~Hz}$, an $\mathrm{AC}$ amplitude of $5 \mathrm{mV}$ and a sampling rate of 100 points. All measurements were performed in PBS containing $2 \mathrm{mM}$ $\mathrm{K}_{3}\left[\mathrm{Fe}(\mathrm{CN})_{6}\right] / \mathrm{K}_{4}\left[\mathrm{Fe}(\mathrm{CN})_{6}\right](1: 1)$ mixture, used as a redox marker. In all cases impedance data were registered in the following order after each electrode successive modification: (1) bare electrode; (2) aptamer immobilization step and (3) protein detection. The impedance spectra were plotted in the form of complex plane diagrams (Nyquist plots, $\left.-Z_{\mathrm{im}} v S . \mathrm{Z}_{\mathrm{re}}\right)$ and fitted to a theoretical curve corresponding to the equivalent circuit with FRA software. The equivalent circuit is called Randles Circuit, as shown in Fig. 2a. The parameter $R_{s}$, corresponds to the resistance of the solution, $R_{c t}$ is the charge transfer resistance between the solution and the electrode surface, whilst capacitor (C) is associated with the double-layer capacitance and the Warburg parameter (W) corresponds to the diffusion of the redox probe. For all performed fittings, the chisquare goodness-of-fit test was thoroughly checked to verify calculations. In all cases, calculated values for each circuit remained in the range of 0.0003-0.15 much lower than the tabulated value for 100 degrees of freedom (77.93 at $95 \%$ confidence level). In this work, we focused on the variation of the resistance to charge transfer $\left(R_{c t}\right)$. In order to compare the results obtained from the different electrodes used, and to obtain independent and reproducible results, relative and normalized signals were needed (34). Thus, the $\Delta_{\text {ratio }}$ value was defined according to the following equations:

$$
\begin{gathered}
\Delta_{\text {ratio }}=\Delta_{\mathrm{s}} / \Delta_{\mathrm{p}} \\
\Delta_{\mathrm{s}}=\mathrm{R}_{\mathrm{ct}(\text { AptLysCOX/TRAN) }}-\mathrm{R}_{\mathrm{ct} \text { (electrode-buffer) }} \\
\Delta_{\mathrm{p}}=\mathrm{R}_{\mathrm{ct} \text { (AptLysCOX/TRAN-Lys) }}-\mathrm{R}_{\mathrm{ct} \text { (electrode-buffer) }}
\end{gathered}
$$

Where $\mathrm{R}_{\mathrm{ct}}$ (AptLysCOX/TRAN-Lys) was the electron transfer resistance value measured after incubation with the protein, $\mathrm{R}_{\mathrm{ct}}$ (AptLysCOX/TRAN) was the electron transfer resistance value 
measured after aptamer immobilization on the electrode and $R_{c t}$ (electrode-buffer) was the electron transfer resistance of the blank electrode and buffer.

\section{Results and discussion}

\subsection{Immobilization of aptamer onto the electrode surface.}

Aptamer immobilization is a very crucial step in biosensor construction. In this work, the aptamers were immobilized onto the electrode surface by covalent binding via diazonium salt. In this method, the electrochemical reduction of a diazonium salt creates an aryl centered radical after the spontaneous elimination of dinitrogen. The resulting aryl radical can then form a robust covalent bond with the conducting electrode surface. This technique presents some advantages such as higher stability of the electrode surface, ease of preparation, and the ability to synthesize diazonium salts with a wide range of functional groups, in this case with carboxylic groups(35). For that, SPCEs were modified by electrochemical reduction of the in situ generated 4-carboxyphenyl diazonium salts by linear sweep voltammetry as illustrated in Fig. 2. After the activation by EDC and NHS mixture, both types of aptamers were linked to the activated carboxylic group via amide bond formation.

$<$ Figure 2 $>$

\subsection{Electrochemical characterization of the aptasensors}

$\mathrm{CV}$ and EIS techniques are widely used to confirm the electrode/electrolyte interfacial properties at the different steps of aptasensor fabrication. Thus, the different stages of the aptasensor preparation were investigated by recording cyclic voltammograms and impedance spectrums of modified electrode in the presence of the reversible $\left[\mathrm{Fe}(\mathrm{CN})_{6}\right]^{4-/ 3-}$ redox system.

\subsubsection{Cyclic voltammetry characterizations}

In $\mathrm{CV}$, the change in peak current and peak to peak separation in voltammograms at different modification steps can be related to the electron transfer resistance. As shown 
in Figure 3a and 3b, at the bare SPE electrodes, a pair of well-defined reversible redox peaks with high peak currents was observed. After the modification with diazonium salt, the peak current of $\left[\mathrm{Fe}(\mathrm{CN})_{6}\right]^{4-/ 3-}$ redox couple clearly decreased due to the inhibition of the electron transfer resistance between the electrochemical probe and the electrode surface. When the electrode was modified with $\mathrm{EDC} /$, the peak current increased and the peak to peak potential separation decreased due to the neutrally charged NHS ester. After immobilization of aptamer probe on the electrode surface, the peak current clearly decreased and the peak to peak potential separation increased, accounting for increased resistance to the charge transfer across aptamer probe attached on the electrode and reducing the effective surface area and available active sites for the electron transfer process. Then, after modifying the electrode surface with ethanolamine, the unreacted carboxyl groups were blocked and the peak current decreased while the peak to peak potential separation increased. When the electrodes were incubated with BSA, the peak current further decreased and the peak to peak potential separation increased due to the big sterical hindrance of BSA. Finally, when the aptasensor was incubated with Lys, it could be found that the voltammetric peak response further decreased and peak potential separations increased due to sterical hindrance of the protein.

$<$ Figure 3 $>$

\subsubsection{Impedance characterizations}

The aptasensor preparation process was also characterised by EIS, in this case, the diameter of the semicircle of the Nyquist plots indicate the magnitude of the electron transfer resistance, $\mathrm{R}_{\mathrm{ct}}$. As can be seen in Figure $4 \mathrm{a}$ and $4 \mathrm{~b}$, prior to the diazoninum cation, the $\mathrm{R}_{\mathrm{ct}}$ of the non-modified electrodes were small due to low resistance of bare electrodes for redox probe. After the electrodes were modified with diazonium salt, the $\mathrm{R}_{\mathrm{ct}}$ were increased due to the formation of an organic layer on the electrodes surfaces. The layers with terminal negatively charged on the electrode surface acted as electrostatic barrier and reduced the ability of the redox probe to access the layer. When the modified electrodes were activated by EDC/NHS, decrease of $\mathrm{R}_{\mathrm{ct}}$ was observed. This could be due to the fact that the carboxyl groups on the electrode surfaces were replaced by NHS ester, thus the neutrally charged NHS ester promoted the transfer of the negative probe onto the electrode surface. Subsequently, when AptLysCOX or 
AptLysTRAN were immobilized, the $\mathrm{R}_{\mathrm{ct}}$ increased due to the blocking and repulsive property of negatively charged aptamers for the redox probe with negatively charged $\left[\mathrm{Fe}(\mathrm{CN})_{6}\right]^{4-/ 3-}$. After incubating with ethanolamine, the $\mathrm{R}_{\mathrm{ct}}$ decreased due to the blocking of the unreacted carboxyl group. Then, when the electrodes were modified with BSA, the $\mathrm{R}_{\mathrm{ct}}$ were further increased due to hindrance of BSA. After incubating aptasensors with Lys, the $\mathrm{R}_{\mathrm{ct}}$ were increased, although the iso electric point of the Lys is about 11. This fact could be explained that in these cases the sterical factor dominates over the electrostatic factor. In the case of the aptasensor with AptLysTRAN the value of $\mathrm{R}_{\mathrm{ct}}$ is greater than the obtained with AptLysCOX, thus AptLysTRAN could be more sensitive than AptLysCOX.

The results were consistent with the CV voltammograms in both cases. However, EIS results presented more apparent differences for different modification steps, indicating better sensitivity compared to CV results.

$<$ Figure 4 $>$

\subsection{Optimization of the concentrations of aptamers}

The amount of aptamer immobilized onto the electrode surface is an important parameter to optimize prior to perform the detection of desired analyte. Higher Apt concentration could provide more active sites available for the recognition of Lys, but also influence the sensitivity. In order to obtain the optimal concentrations of AptLysCOX and AptLysTRAN to be used in the biosensing protocol, response was evaluated with increasing concentrations of each aptamer. The optimal concentration was evaluated by the changes in the $\Delta_{\text {ratio. }}$ Fig. $5 \mathrm{a}$ and $\mathrm{b}$ shows the calibration curve of AptLysCOX and AptLysTRAN. It can be seen that the signals $\left(\Delta_{\text {ratio }}\right)$ reached a plateau showing a steady performance. A compromise between the signals generated and the cost of the aptamers led to the selection of concentrations of $20 \mu \mathrm{M}$ and $10 \mu \mathrm{M}$, for AptLysCOX and AptLysTRAN respectively.

$<$ Figure 5 $>$

\subsection{Analytical performance of the aptasensors}


Analytical performance of the two aptasensors for lysozyme detection was compared in terms of LOD, linear range and recovery values. In order to obtain the sensitivity of the aptasensors, calibration curves were constructed by using different concentrations of Lys. As can be seen from Fig. 6, the response increased up to the Lys concentration of 1 $\mu \mathrm{M}$ for both the aptasensors. This could be due to the fact that concentrations higher than these values cause saturation on the sensor surface. As can be observed in Table 1, aptasensor with AptLysTRAN showed a higher sensitivity than the aptasensor with AptLysCOX, $0.210 \mu \mathrm{M}^{-1}$ and $0.103 \mu \mathrm{M}^{-1}$, respectively. In addition, the lowest LOD corresponds to aptasensor with AptLysTRANS which is $31.7 \mathrm{nM}$, whilst the other aptasensor showed a LOD value of $725 \mathrm{nM}$. However, the best reproducibility value, 2.92\%, corresponded to the aptasensor using AptLysCOX. As the results showed, both aptasensors were capable of detecting Lys with high sensitivity and reproducibility.

$<$ Figure 6>

$<$ Table 1 $>$

\subsection{Selectivity of the aptasensors}

The selectivity of the aptasensors for some proteins such as BSA, casein and cytochrome c was assessed. As can be seen in Fig. 6, the presence of these proteins caused negligible response in both aptasensors compared with the same concentration of Lys. However, the aptasensor modified with AptLysTRAN showed more selectivity than the aptasensor with AptLysCOX. These results are strong proof of the highly selective detection of Lys. No cross reactions were observed from similar interfering proteins, even in the case of cytochrome c, which is structurally similar to Lys.

$<$ Figure $7>$

\subsection{Application to spiked wine samples}

In order to check the feasibility of the aptasensors to detect lysozyme in wine samples, wine aliquots were spiked with Lys at different concentrations range from 0.5 to $1.5 \mu \mathrm{M}$, 
and these samples were tested using both developed aptasensors. The obtained recovery rates are illustrated in Table 2. The developed methods exhibit good recoveries ranging from $96.4 \%$ to $102 \%$, indicating the suitability of the developed aptasensor for Lys detection in wine samples.

$<$ Table 2>

\section{Conclusion}

In the present work, two different aptasensors were designed and compared to detect lysozyme. Both aptasensors showed high sensitivity, reproducibility, fast response, selectivity and low detection limits. However, aptasensor using AptLysTRAN showed better sensitivity and LOD values as compared to AptLysCOX. The calculated LOD is many folds lower than the maximum amount allowed to be added in wine as prescribed by the International Organization of Wine and Vine (OIV). In addition, the aptasensors were used for detection of lysozyme in spiked wine samples and very promising recovery values were obtained in the range 96.4 to $102 \%$. According to the results presented here, impedimetric sensors based on screen-printed carbon electrodes could provide a promising platform for fabrication of aptamer- based disposable biosensors for wine analysis and potentially for other practical applications.

\section{Acknowledgments}

Cristina Ocaña thanks the support of Ministry of Science and Innovation (MICINN, Madrid, Spain) for the pre-doctoral grant. Manel del Valle acknowledges the support from the program ICREA Academia. Alina Vasilescu acknowledges the financial support of CNDI - UEFISCDI, through project PHC Brancusi PN-II-CT-RO-FR-2012-10012 .

\section{References}

1. Schindler, M., Assaf, Y., Sharon, N., and Chipman, D. M. (1977) Biochemistry 16, $423-$ 431

2. Mink, S. N., Bose, R., Roberts, D. E., Jacobs, H., Duke, K., Bose, D., Cheng, Z. Q., and Light, R. B. (2005) Journal of molecular and cellular cardiology 39, 615-625 
3. Smith, L. E. H., Mohr, L. H., and Raftery, M. A. (1973) Journal of the American Chemical Society 95, 7497-7500

4. Lasanta, C., Roldán, A., Caro, I., Pérez, L., and Palacios, V. (2010) Food Control 21, $1442-$ 1447

5. Wine, I. O. o. V. a. (2013) International Code of Oenological Practices http://www.oiv.int/oiv/info/enplubicationoiv\#code

6. Kondeková, M., Maier, V., Ginterová, P., Marák, J., and Ševčík, J. (2014) Food Chemistry 153, 398-404

7. Kvasnička, F. (2003) ELECTROPHORESIS 24, 860-864

8. Ravelo-Perez, L. M., Asensio-Ramos, M., Hernandez-Borges, J., and Rodriguez-Delgado, M. A. (2009) Electrophoresis 30, 1624-1646

9. Chen, C., Sun, X.-M., and Li, B.-H. (2011) Chinese Journal of Analytical Chemistry 39, 9194

10. Samuelson, K. J., Rupnow, J. H., and Froning, G. W. (1985) Poultry science 64, 14881490

11. Chander, R., and Lewis, N. (1980) European J. Appl. Microbiol. Biotechnol. 10, 253-258

12. Wine, I. O. o. V. a. (2014) OIV-COMEX 502-2012-Revision of the Limit of Detection and Limit of Quantification Related to Potentially Allergenic Residues of Fining Agent Proteins in Wine.

13. Pascual, R. S., Gee, J. B. L., and Finch, S. C. (1973) New England Journal of Medicine 289, 1074-1076

14. Porstmann, B., Jung, K., Schmechta, H., Evers, U., Pergande, M., Porstmann, T., Kramm, H.-J., and Krause, H. (1989) Clinical Biochemistry 22, 349-355

15. Vasilescu, A., Gaspar, S., Mihai, I., Tache, A., and Litescu, S. C. (2013) Analyst 138, 3530-3537

16. Chen, C., Zhao, J., Jiang, J., and Yu, R. (2012) Talanta 101, 357-361

17. Xie, D., Li, C., Shangguan, L., Qi, H., Xue, D., Gao, Q., and Zhang, C. (2014) Sensors and Actuators B: Chemical 192, 558-564

18. Ronkainen, N. J., Halsall, H. B., and Heineman, W. R. (2010) Chem. Soc. Rev. 39, 17471763

19. Frew, J. E., and Hill, H. A. O. (1987) Anal. Chem. 59, 933A-944A

20. McDonald, J. R. (1987) Impedance Spectroscopy, John Wiley, New York

21. Lisdat, F., and Schafer, D. (2008) Anal. Bioanal. Chem. 391, 1555-1567

22. Bonanni, A., Esplandiu, M. J., and del Valle, M. (2010) Biosens. Bioelectron. 26, 12451251

23. Bardea, A., Patolsky, F., Dagan, A., and Willner, I. (1999) Chem. Comm., 21-22

24. Loo, A. H., Bonanni, A., Ambrosi, A., Poh, H. L., and Pumera, M. (2012) Nanoscale 4, 921-925

25. Randviir, E. P., and Banks, C. E. (2013) Anal. Method. 5, 1098-1115

26. Luzi, E., Minunni, M., Tombelli, S., and Mascini, M. (2003) TrAC Trends in Analytical Chemistry 22, 810-818

27. Tombelli, S., Minunni, M., and Mascini, M. (2005) Biosens. Bioelectron. 20, 2424-2434

28. Jayasena, S. D. (1999) Clin Chem 45, 1628-1650

29. Jenison, R. D., Gill, S. C., Pardi, A., and Polisky, B. (1994) Science 263, 1425-1429

30. Kirby, R., Cho, E. J., Gehrke, B., Bayer, T., Park, Y. S., Neikirk, D. P., McDevitt, J. T., and Ellington, A. D. (2004) Anal. Chem. 76, 4066-4075

31. Tran, D. T., Janssen, K. P., Pollet, J., Lammertyn, E., Anne, J., Van Schepdael, A., and Lammertyn, J. (2010) Molecules (Basel, Switzerland) 15, 1127-1140

32. Cox, J. C., and Ellington, A. D. (2001) Bioorganic \& medicinal chemistry 9, 2525-2531 
33. Mihai, I., Vezeanu, A., Polonschii, C., Albu, C., Radu, G.-L., and Vasilescu, A. (2015) Sensors and Actuators B: Chemical 206, 198-204

34. Bonanni, A., Esplandiu, M. J., Pividori, M. I., Alegret, S., and del Valle, M. (2006) Anal. Bioanal. Chem. 385, 1195-1201

35. Ocaña, C., and del Valle, M. (2013) Microchim. Acta, 1-9 


\section{Tables}

Table 1. Summary of regression plots obtained for developed aptasensors.

\begin{tabular}{|c|c|c|c|c|c|c|}
\hline Aptasensor & Regression plot & $\begin{array}{l}\text { Sensitivity } \\
\qquad\left(\mu M^{-1}\right)\end{array}$ & $\begin{array}{c}\text { Linear } \\
\text { Range } \\
(\mu M)\end{array}$ & $\begin{array}{l}L O D \\
(n M)\end{array}$ & $\begin{array}{c}\% \\
R S D^{*}\end{array}$ & $\begin{array}{c}\text { Correlation } \\
\text { Coeficient } \\
\text { (r) }\end{array}$ \\
\hline AptLysCOX & $\Delta_{\text {ratio }}=1.20+0.103[$ Lys $]$ & 0.103 & $\begin{array}{c}0.025- \\
1\end{array}$ & 725 & 2.92 & 0.99 \\
\hline AptLysTRAN & $\Delta_{\text {ratio }}=1.52+0.210[$ Lys $]$ & 0.210 & $\begin{array}{c}0.025- \\
1\end{array}$ & 31.7 & 9.29 & 0.97 \\
\hline
\end{tabular}

Table 2. Recovery studies performed in spiked wine samples for applicability of aptasensors $(n=3)$.

\begin{tabular}{l|llll} 
Aptasensor & $\begin{array}{l}\text { Spiked } \\
(\mu M)\end{array}$ & $\begin{array}{l}\text { Found } \\
(\mu M)\end{array}$ & \%Recovery & \%RSD \\
\hline AptLysCOX & 1.5 & 1.53 & 102 & 8.04 \\
& 1 & 1.01 & 100.8 & 2.62 \\
& 0.8 & 0.81 & 98.4 & 2.93 \\
AptLysTRAN & 1 & 0.996 & 99.6 & 3.78 \\
& 0.8 & 0.81 & 101.3 & 15.5 \\
& 0.5 & 0.48 & 96.4 & 5.85 \\
* Correspond to the recovery values (n=3). &
\end{tabular}




\section{Figures and Captions}

Figure 1. Schematic representation of developed experimental procedure.

Figure 2. a) Equivalent circuit, called Randles Circuit, used for fitting the impedance data. b) Linear sweep voltammetry for the in situ generated 4-carboxylphenyl in diazotation mixture at SPE.

Figure 3.a) Cyclic voltammetry diagrams of $2 \mathrm{mM}\left[\mathrm{Fe}(\mathrm{CN})_{6}\right]^{3-/ 4-}$ at scan rate of $100 \mathrm{mVs}^{-1}$ for: (a) bare electrode, (b) SPC modified with diazonium salt, (c) SPC modified with diazonium salt and EDC/NHS, (d) SPC modified with diazonium saltEDC/NHS-AptLysCOX, (e)SPC modified with diazonium salt-EDC/NHSAptLysCOX-ethanolamine, (f)SPC modified with diazonium salt-EDC/NHSAptLysCOX-ethanolamine-BSA, SPC modified with diazonium salt-EDC/NHSAptLysCOX-ethanolamine-BSA-Lys . b) Cyclic voltammetry diagrams of $2 \mathrm{mM}$ $\left[\mathrm{Fe}(\mathrm{CN})_{6}\right]^{3-/ 4-}$ at scan rate of $100 \mathrm{mVs}^{-1}$ for: (a) bare electrode, (b) SPC modified with diazonium salt, (c) SPC modified with diazonium salt and EDC/NHS, (d) SPC modified with diazonium salt-EDC/NHS-AptLysTRAN, (e)SPC modified with diazonium saltEDC/NHS-AptLysTRAN-ethanolamine, (f)SPC modified with diazonium saltEDC/NHS-AptLysTRAN-ethnanolamine-BSA, (g)SPC modified with diazonium saltEDC/NHS-AptLysTRAN-ethnanolamine-BSA

Figure 4. a) Nyquist diagrams for each step of the protocol of: (a) bare electrode, (b) SPCE modified with diazonium salt, (c) SPCE modified with diazonium salt and EDC/NHS, (d) SPCE modified with diazonium salt-EDC/NHS-AptLysCOX, (e)SPCE modified with diazonium salt-EDC/NHS-AptLysCOX-ethanolamine, (f)SPCE modified with diazonium salt-EDC/NHS-AptLysCOX-ethanolamine-BSA, (g)SPCE modified with diazonium salt-EDC/NHS-AptLysCOX-ethanolamine-BSA-Lys. b) Nyquist diagrams for every step of the protocol of: (a) bare electrode, (b) SPCE modified with diazonium salt, (c) SPCE modified with diazonium salt and EDC/NHS, (d) SPCE modified with diazonium salt-EDC/NHS-AptLysTRAN, (e) SPCE modified with diazonium salt-EDC/NHS-AptLysTRAN-ethanolamine, (f)SPCE modified with diazonium salt-EDC/NHS-AptLysTRAN-ethanolamine-BSA, (g)SPCE modified with diazonium salt-EDC/NHS-AptLysTRAN-ethanolamine-BSA-Lys. All experiments were performed in PBS solution and all EIS measurements were performed in PBS solution containing $2 \mathrm{mM} \mathrm{M} \mathrm{K}_{3}\left[\mathrm{Fe}(\mathrm{CN})_{6}\right] / \mathrm{K}_{4}\left[\mathrm{Fe}(\mathrm{CN})_{6}\right]$. 
Figure 5. a) Optimization of the concentration of AptLysCOX. b) Optimization of the concentration of AptLysTRAN. Optimization experiments were performed with $0.5 \mu \mathrm{M}$ of Lys in BB solution and all EIS measurements were performed in PBS solution containing $2 \mathrm{mM} \mathrm{K}_{3}\left[\mathrm{Fe}(\mathrm{CN})_{6}\right] / \mathrm{K}_{4}\left[\mathrm{Fe}(\mathrm{CN})_{6}\right]$. Uncertainty values corresponding to replicated experiments $(n=3)$.

Figure 6.Calibration curves of: a) aptasensor using AptLysCOX and b) aptasensor using AptLysTRAN. Uncertainty values corresponding to replicated experiments $(n=3)$.

Figure 7.a) Selectivity of the aptasensor using AptLysCOX and b) Selectivity of the aptasensor using AptLysTRAN to Lys, casein, BSA and cytochrome C at $0.5 \mu \mathrm{M}$, respectively. Error bars are obtained based on three independent measurements. 
Figure 1.

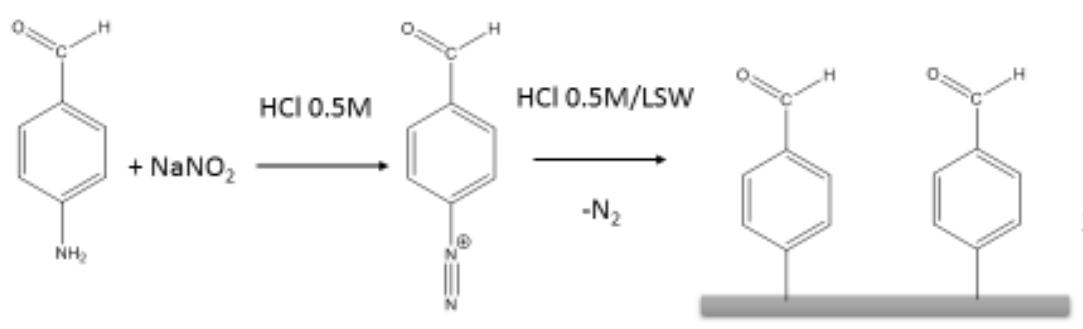

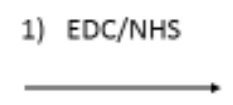

2) AptLysCOX or TRAN

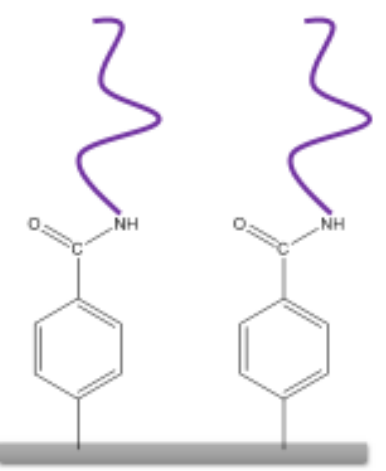

1) Etanolamine

2) BSA
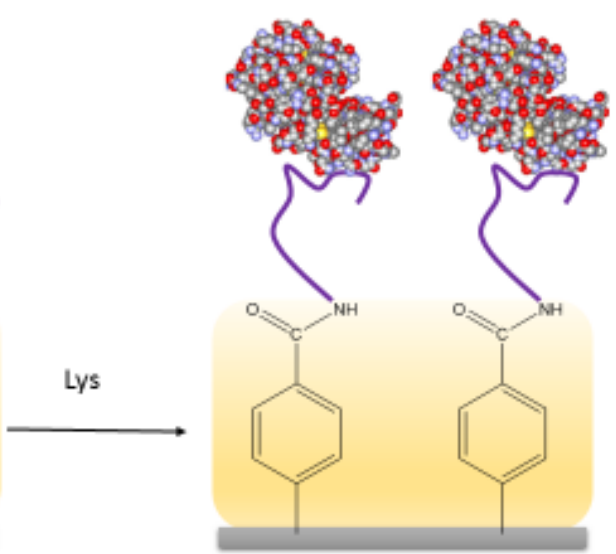

17 
Figure 2.
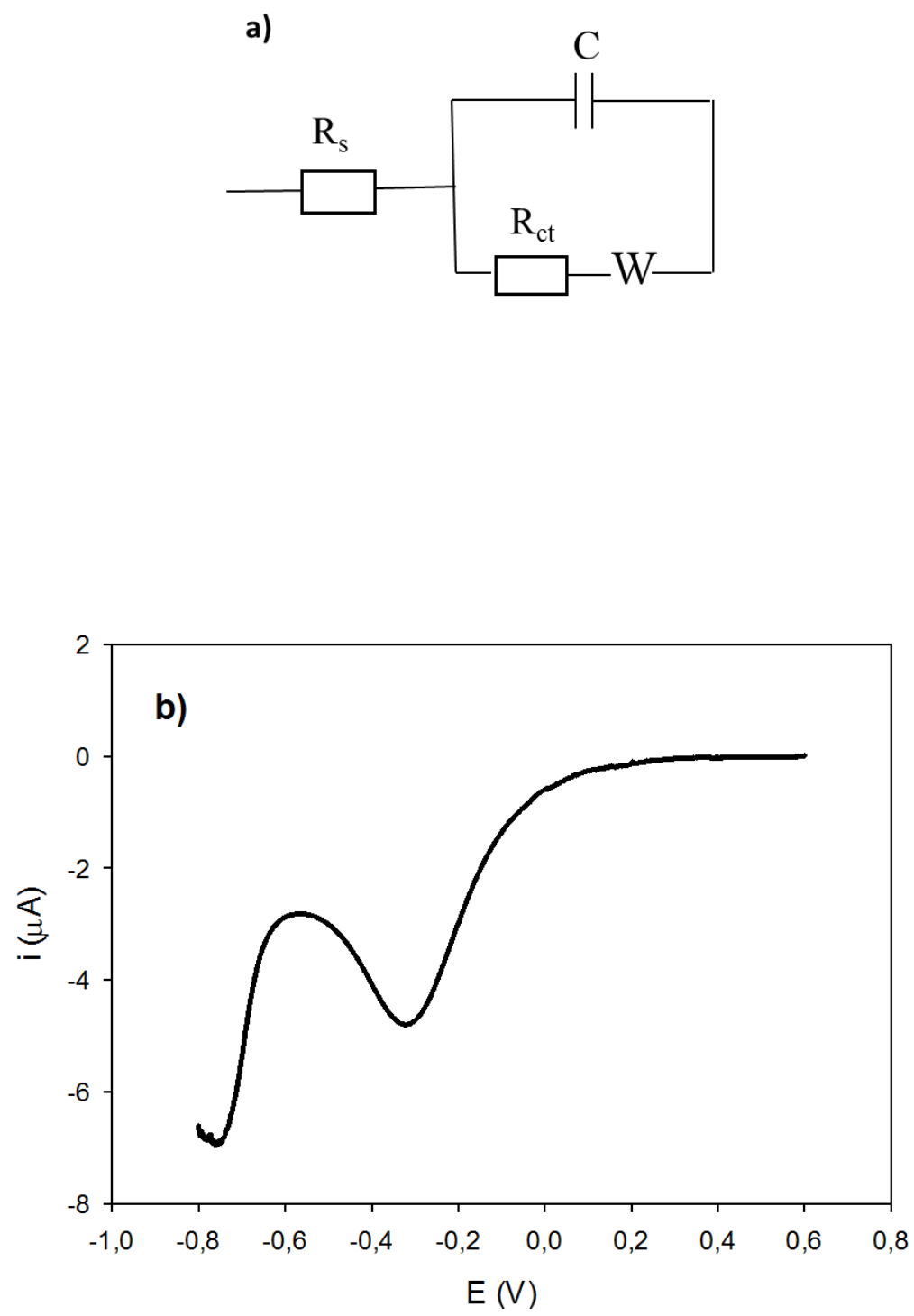
Figure 3.
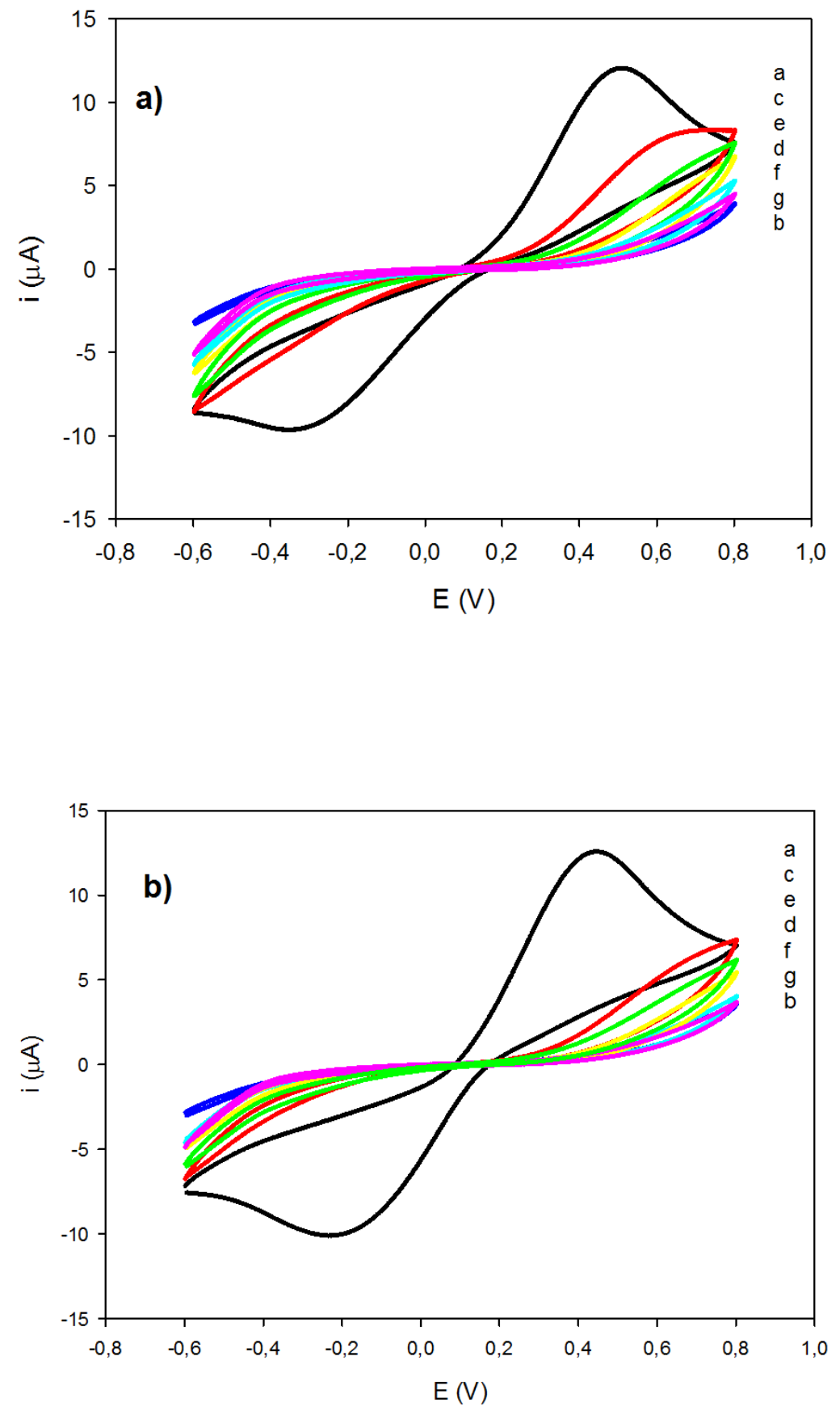
Figure 4.
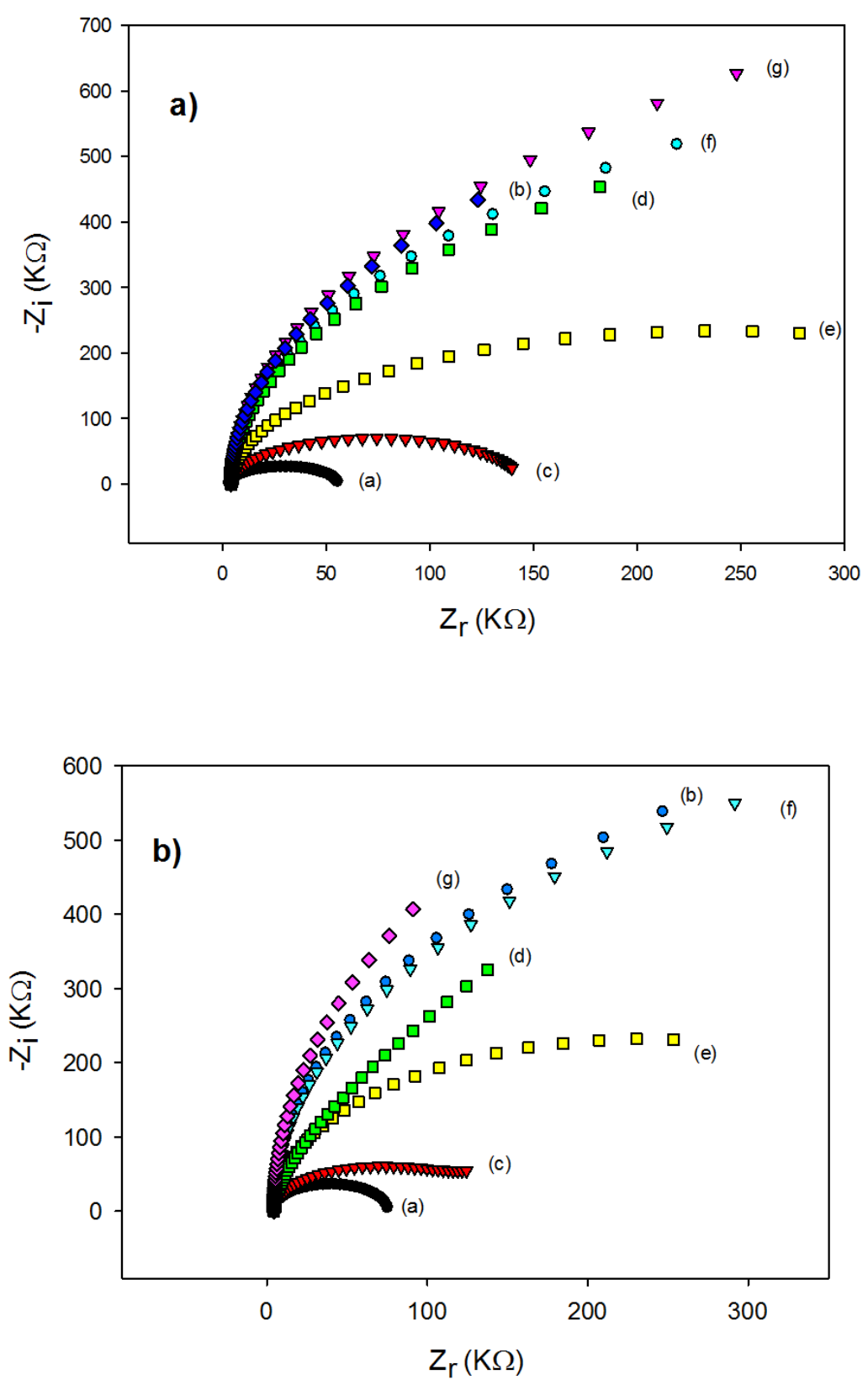
Figure 5.
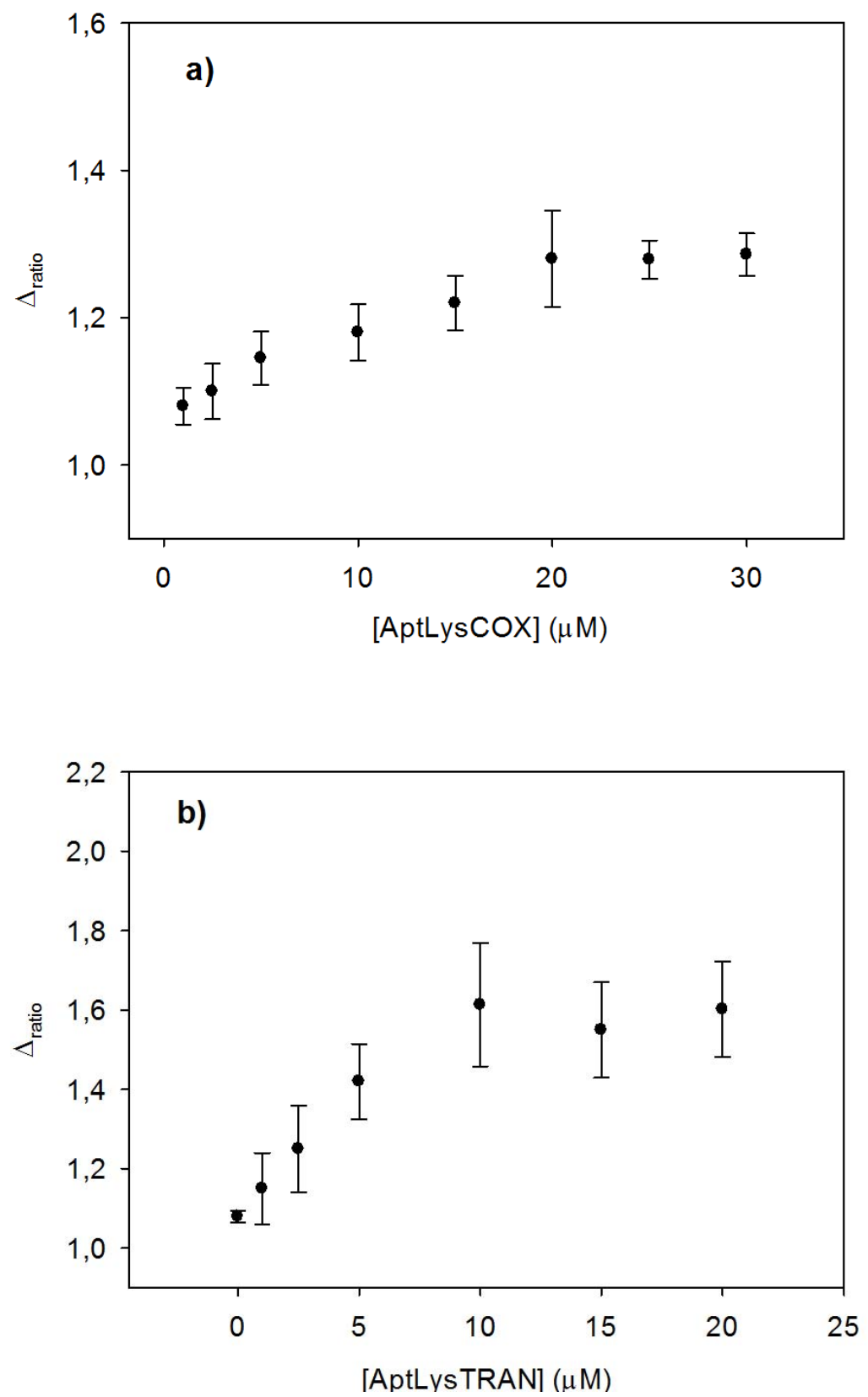
Figure 6.
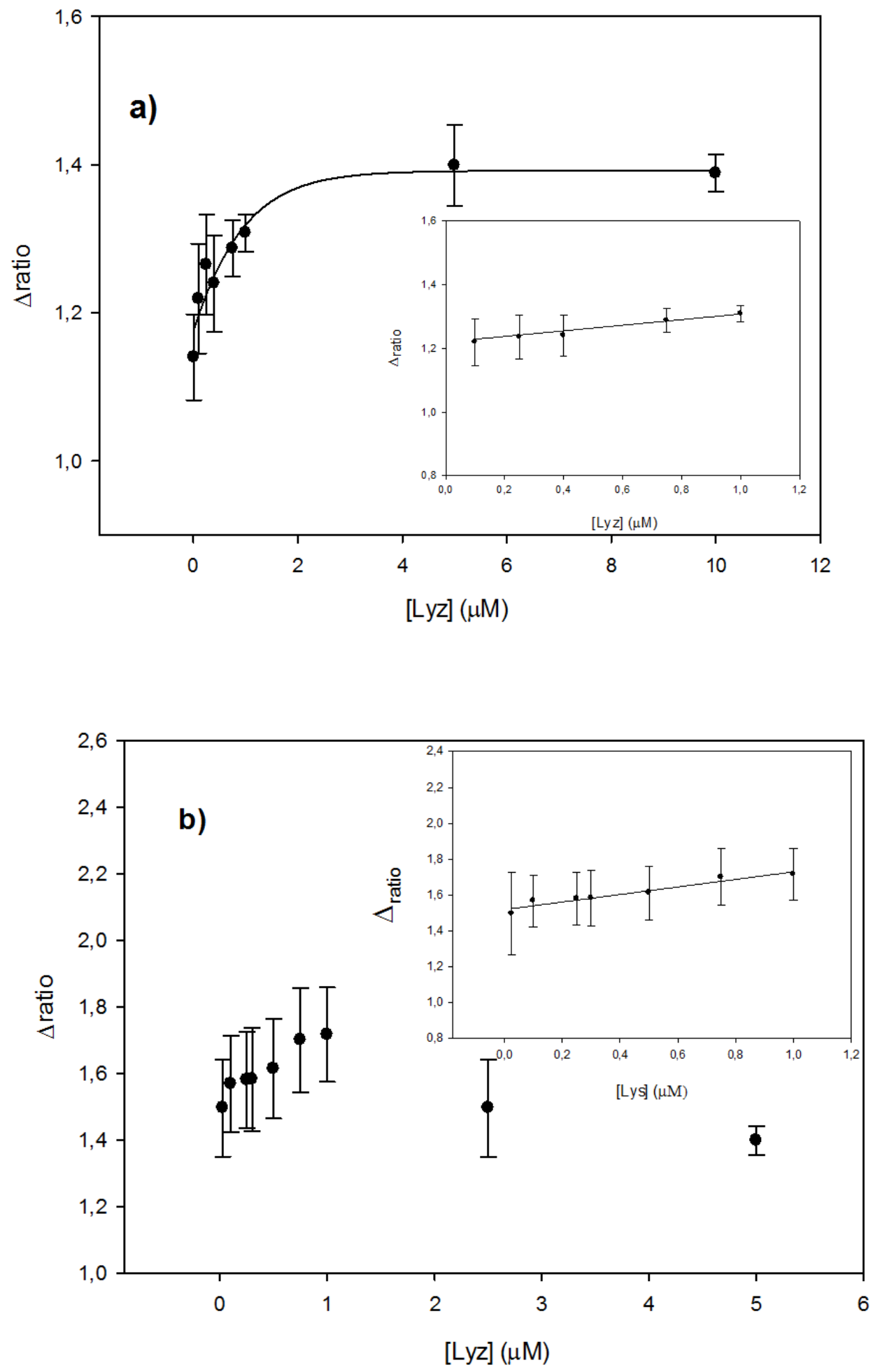
Figure 7.
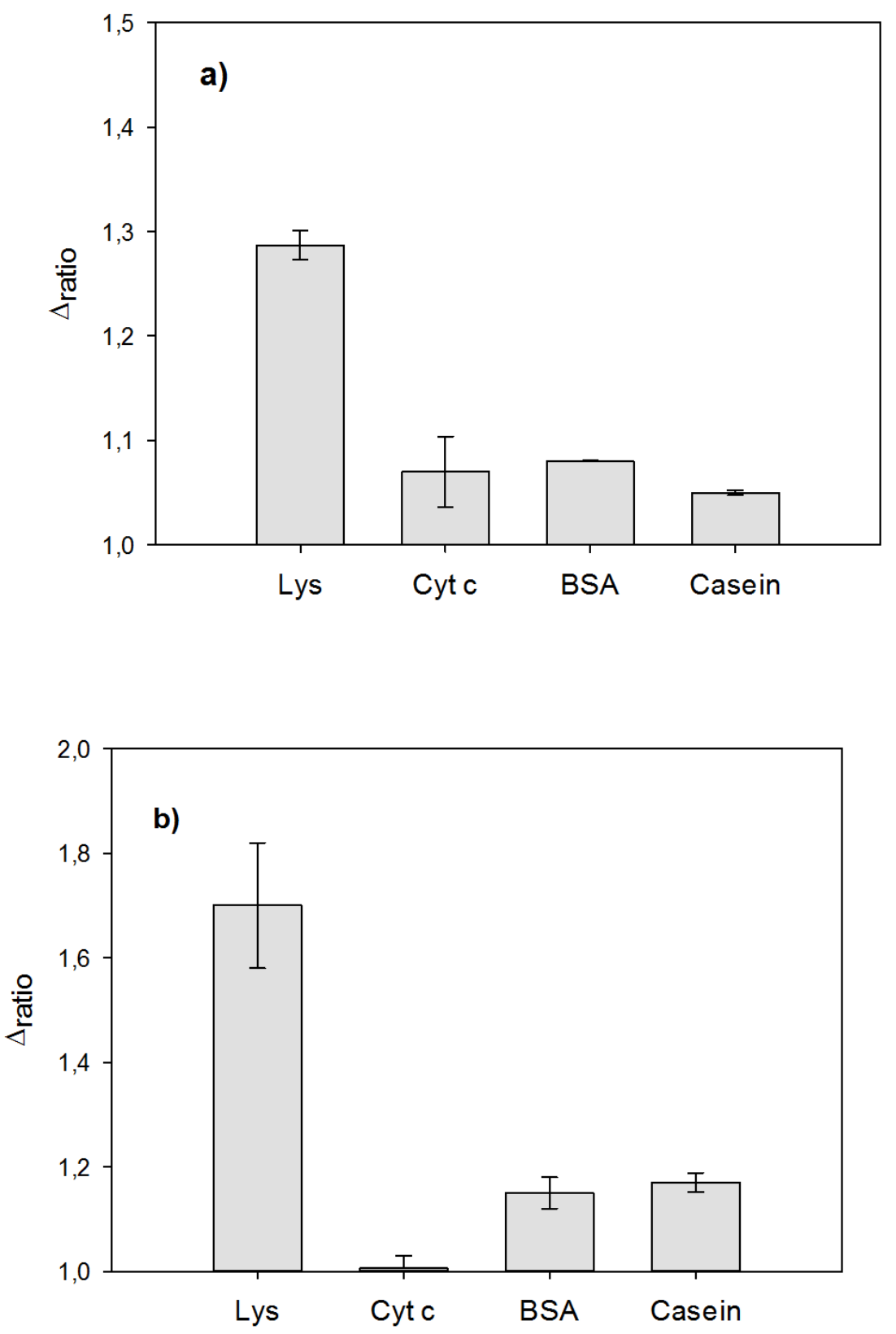